\title{
Approaches to investigating transmission of spongiform encephalopathies in domestic animals using BSE as an example
}

\author{
Marion Mathieson SiMmons ${ }^{1 *}$, John SPIROPOULOs ${ }^{1}$, Stephen Anthony Charles \\ HAWKINS ${ }^{1}$, Susan Jane BELlWORTHY ${ }^{1}$, Susan Carol TONGUE ${ }^{2}$ \\ ${ }^{1}$ Pathology Department, Veterinary Laboratories Agency, Woodham Lane, New Haw, Addlestone, \\ Surrey, KT15 3NB, UK \\ ${ }^{2}$ Centre for Epidemiology and Risk Analysis, Veterinary Laboratories Agency, Woodham Lane, New Haw, \\ Addlestone, Surrey, KT15 3NB, UK
}

(Received 29 October 2007; accepted 12 February 2008)

\begin{abstract}
Bovine spongiform encephalopathy was a novel spongiform encephalopathy, in an hitherto unaffected species, that had characteristics of a point source epidemic, with an agent that could have been incorporated into a wide variety of feedstuffs and iatrogenically administered to naïve populations, and there was early evidence that it was not restricted to bovines. It was vital to establish, albeit experimentally, which other species might be affected, and whether the epidemic could be maintained by natural transmission, if the source was removed. In contrast, scrapie has been endemic throughout Great Britain for centuries, is maintained naturally (even if we don't know exactly how) and has a known host range. The principles, process and integration of evidence from different types of studies, however, are similar for both of these transmissible spongiform encephalopathies (TSE) and can be applied to any emerging or suspected spongiform encephalopathy. This review discusses the experimental approaches used to determine TSE transmissibility and infectivity and how they relate to natural disease and control measures.
\end{abstract}

TSE / transmission / natural / experimental / domestic animals

Table of contents

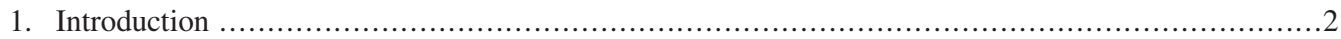

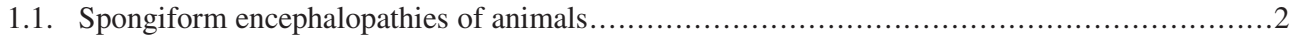

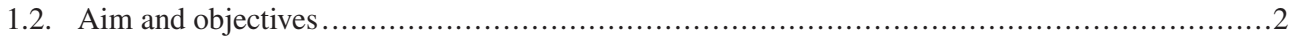

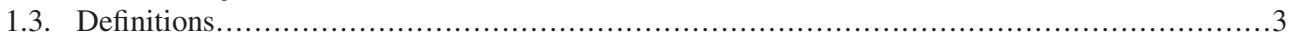

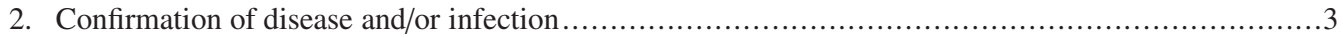

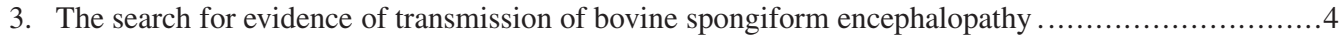

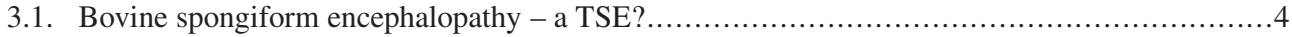

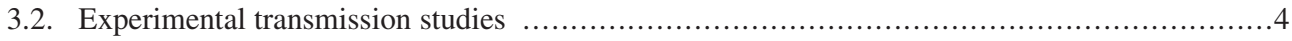

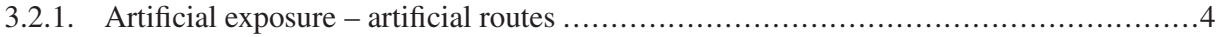

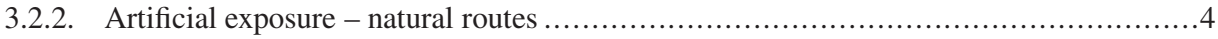

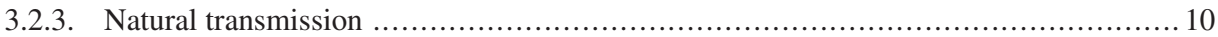

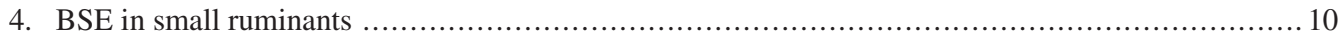

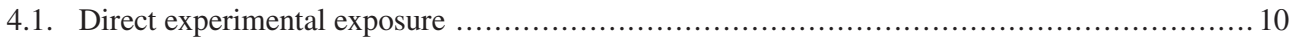

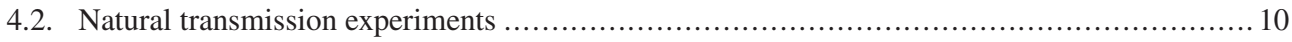

\footnotetext{
* Corresponding author:

m.m.simmons@vla.defra.gsi.gov.uk
} 


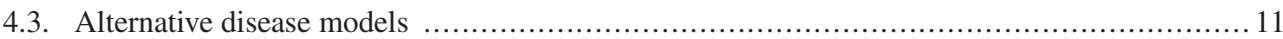

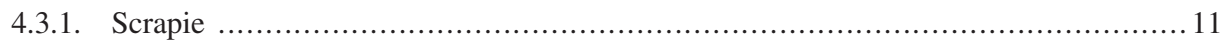

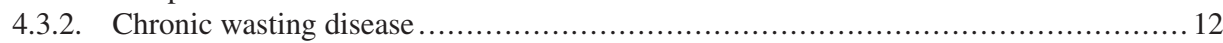

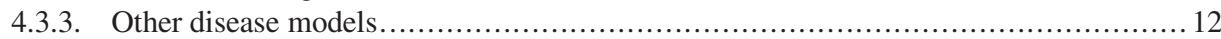

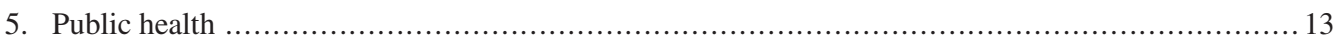

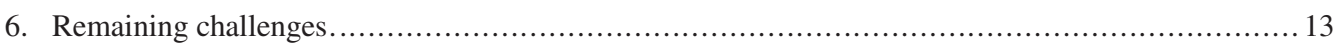

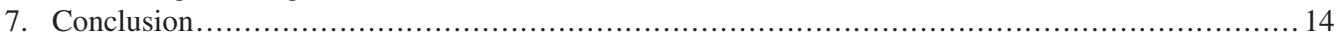

\section{INTRODUCTION}

\subsection{Spongiform encephalopathies of animals}

The spongiform encephalopathies of animals include scrapie, chronic wasting disease (CWD), transmissible mink encephalopathy (TME), bovine spongiform encephalopathy (BSE), feline spongiform encephalopathy (FSE), the spongiform encephalopathies seen in non-domestic captive ungulate species such as eland, oryx and greater kudu, and captive ostriches [85-87]. Spongiform change can also be seen in other diseases, such as rabies, other viral diseases [14, 29, 88], and hepatic encephalopathies. They may be encountered as a genetic or congenital problem $[62,63$, $102]$, as an incidental finding in normal sheep [126], or even as an artefact [108].

However, the only observed natural animalto-animal transmission of a spongiform encephalopathy occurs in ruminants: scrapie in small ruminant species, CWD in deer and elk, and possibly BSE in small ruminants (although this latter example has only been observed in an experimental flock [8]). Natural spongiform encephalopathies in other species, including humans, are either genetic in origin (e.g. Gerstmann-Sträussler-Scheinker disease, fatal familial insomnia) or have been linked predominantly with an idiopathic transmission mechanism i.e. exposure to contaminated feedstuffs (TME, BSE, FSE, and kuru in humans). There is no recorded occurrence of spongiform encephalopathies being able to transmit effectively within non-ruminant species.

The naturally occurring transmissible spongiform encephalopathies (TSE) are invariably fatal, have long incubation periods and provoke no overt immune response in the host. In some, such as scrapie, there are known genetic effects on whether exposure leads to the development of clinical disease [98, 100]. Additional factors that may affect host susceptibility have been proposed [25, 45,93 ] and there could be other unconfirmed, or even as yet unidentified, factors that might affect host susceptibility.

\subsection{Aim and objectives}

An integral part of the classification of spongiform encephalopathies is whether they are transmissible or not. If it is possible to experimentally transmit "to pass or hand on" [4] i.e. transfer the disease, then it has the potential to be naturally infectious. An infectious disease is one that is due to the "transmission of a specific agent, or its toxic products from an infected person, animal, or reservoir to a susceptible host, either directly or indirectly through an intermediate plant or animal host, vector, or the inanimate environment" [71]. This has implications for disease control strategies; different approaches will be needed if there is an infectious component than if the disease was purely due to a nutritional or genetic cause. It should also be noted that an infectious disease may not be contagious where contagious is defined as "the communication of disease by direct or indirect contact" i.e. it is communicable to other individuals [3].

Experimental approaches to the investigation of whether transmission occurs have become more sophisticated since the start of the 20th century when Cuillé and Chelle first achieved experimental transmission of sheep scrapie via the conjunctival route in France in $1936[17,18]$. This experimental evidence of transmissibility was confirmed, somewhat unintentionally, by the iatrogenic transmission of scrapie from sheep to sheep via the medium of 
a louping ill vaccine, which led to outbreaks in Great Britain during the 1930s [41].

In this review on the transmission of TSE in animals our first objective is to illustrate the route to the designation of a spongiform encephalopathy as "transmissible", through the example of BSE in the 20th century. The knowledge that a spongiform encephalopathy is transmissible then leads to the question of the relevance of experimental findings to the field situation, where the required outcomes are public health protection, disease control and, ultimately, disease eradication. This then is our second objective; to put transmissibility into a "real-world" context. Scrapie and BSE are our main examples, with other TSE of animals referred to where appropriate. We also aim to briefly highlight some of the challenges and unanswered (or unanswerable) questions that are inevitably raised when a novel spongiform encephalopathy is encountered, and its ability to transmit is investigated.

\subsection{Definitions}

- PrPSc: "Prion protein". An abnormal isoform of a naturally occurring host protein $\left(\mathrm{PrP}^{C}\right)$ which is resistant to proteolysis.

- End-stage/clinical disease: presence of clinical signs and $\mathrm{PrP}^{\mathrm{Sc}}$ in brainstem and/or lymphoreticular system (LRS).

- Positive animal: $\operatorname{PrP}^{\mathrm{Sc}}$ detectable, regardless of location (i.e. central nervous system (CNS), peripheral nervous system, lymphoreticular system) or clinical status.

- Exposed animal: known challenge with positive material, or contact with positive animals or a contaminated environment. May or may not also be in one of the categories above.

- Negative animal: no detectable $\mathrm{PrP}^{\mathrm{Sc}}$ in any tissue tested (must include CNS (if animal dead) and/or LRS).

- Negative control: animal from a flock or farm with good records, no recorded TSE and a feeding history which does not include meat and bone meal supplements.

- Vertical transmission: transmission from one generation to the next via the germline or in utero [11].
- Horizontal transmission: lateral spread to others in the same group and at the same time; spread to contemporaries [11].

- Maternal transmission: there is some difficulty in separating possible horizontal and vertical components to transmission involved with the dam-offspring relationship, and so the term "maternal transmission" is often used in discussion of the transmission of scrapie, maternal transmission being defined as transmission before or immediately after birth.

\section{CONFIRMATION OF DISEASE AND/OR INFECTION}

The absolute nature of the infectious agent poses a unique challenge and is still a contentious issue. Accumulations of diseasespecific prion protein $\left(\mathrm{PrP}^{\mathrm{Sc}}\right)$ in the CNS can be demonstrated in all cases of clinical disease, so the detection of $\mathrm{PrP}^{\mathrm{Sc}}$ is now used to confirm the disease status of a clinically suspect case at post-mortem [76]. $\mathrm{PrP}^{\mathrm{Sc}}$ accumulations in a variety of tissues can also be seen in the absence of clinical signs and the demonstration of their presence is generally considered as evidence of exposure and infection. However, such $\mathrm{PrP}^{\mathrm{Sc}}$ accumulation occurs relatively late in the incubation period of the disease [6, 117], so this reliance on the presence of $\mathrm{PrP}^{\mathrm{Sc}}$ limits in vivo diagnosis of disease, and surveillance for evidence of exposure or infection, with current diagnostic tools [76]. The currently accepted paradigm is that accumulations of $\mathrm{PrP}^{\mathrm{Sc}}$ are not only associated with disease, but are also associated with transmission and infectivity [92]. Whether it is the sole infectious component is still a subject of some dispute. Firstly, naturally occurring $\mathrm{PrP}^{\mathrm{Sc}}$, when used for transmission experiments, is inevitably contained in a suspension of the tissue in which it originated, and therefore the existence of another factor, or factors, coexisting with $\mathrm{PrP}^{\mathrm{Sc}}$, and responsible for infectivity cannot be unequivocally excluded. Secondly, disease has been experimentally produced by tissue suspensions from potentially infected animals in which no $\mathrm{PrP}^{\mathrm{Sc}}$ was demonstrable with current diagnostic tools [69]. However, in order to investigate 
transmission of spongiform encephalopathies, all studies currently use the presence of $\mathrm{PrP}^{\mathrm{Sc}}$ as a confirmatory marker of disease or exposure/infection.

In experimental studies of TSE, the prolonged incubation periods and the availability of resources coupled with welfare considerations may not allow for individual animals to be followed up to the ultimate fatal endpoint. For this reason there is a lexicon of terms that are applied both in experimental studies and surveillance (see Section 1.3.).

\section{THE SEARCH FOR EVIDENCE OF TRANSMISSION OF BOVINE SPONGIFORM ENCEPHALOPATHY}

Experimental transmission studies in a wide range of recipient species have established that many species are susceptible to parenteral exposure with positive tissue from TSE cases under experimental circumstances (e.g. cattle, sheep, goats, cats, mink, deer, elk, exotic ungulates, primates, laboratory rodents). Detailed reviews of these transmissions have been published recently [52] and will not be repeated here.

\subsection{Bovine spongiform encephalopathy - a TSE?}

Following the identification of BSE in cattle [107] and its epidemiological link to contaminated feed [118, 119], the major transmission questions to be addressed, as in any other new disease, were:

- Can it be transmitted?

- Who or what can it be transmitted to in order to determine the potential host range, which food animal species are susceptible, and if there is a public health risk?

- How much is required to achieve transmission/infection, to define infectious dose and host susceptibility?

Then, if and when transmission is achieved:

- What is the pathogenesis of the resulting disease, what is the earliest time at which evidence of exposure can be detected and in which tissue(s)?
- What are the possible routes and mechanisms of transmission under natural as well as experimental conditions?

- What is the relative importance of identified routes and mechanisms in the transmission of the disease under natural conditions in the original host and other species?

Only then can fully effective steps be taken to intervene and minimise any risks to public or animal health that may arise.

\subsection{Experimental transmission studies}

\subsubsection{Artificial exposure - artificial routes}

Some of these questions were addressed for BSE initially by experimental transmission studies (see Tab. I for details [6, 8, 9, $20,21,26,32,35,46,49,54,58-60,72,83$, 97, 109-114, 116, 117, 124]). In the case of BSE, a sense of urgency accompanied these investigations, partly as a consequence of the subsequent emergence of similar disease in a range of other species [57, 64, 125], and partly because infected animals would have entered the human food chain. Historically the most efficient transmission route to use to provide an indication of potential host range susceptibility was that of intracerebral inoculation (i.c.). Initial studies established that transmission of disease to food animal species using CNS tissues from natural cases of BSE in cattle was possible to cattle, sheep, goats and pigs but not chickens.

Table I summarises the experimental challenges that have been undertaken using cattle BSE as a source, and food animal species as recipients. A similar range of studies could be listed for other donor species/strains (in particular scrapie and CWD), and indeed for BSE challenges into non-food animal recipients, but exhaustively listing these is considered to be beyond the scope of this paper.

\subsubsection{Artificial exposure - natural routes}

The next stage was to establish if susceptibility could also be demonstrated by more natural routes of infection. The natural route(s) for the transmission of TSE in the field is still not known, but for most experimental purposes the oral route is considered appropriate. 


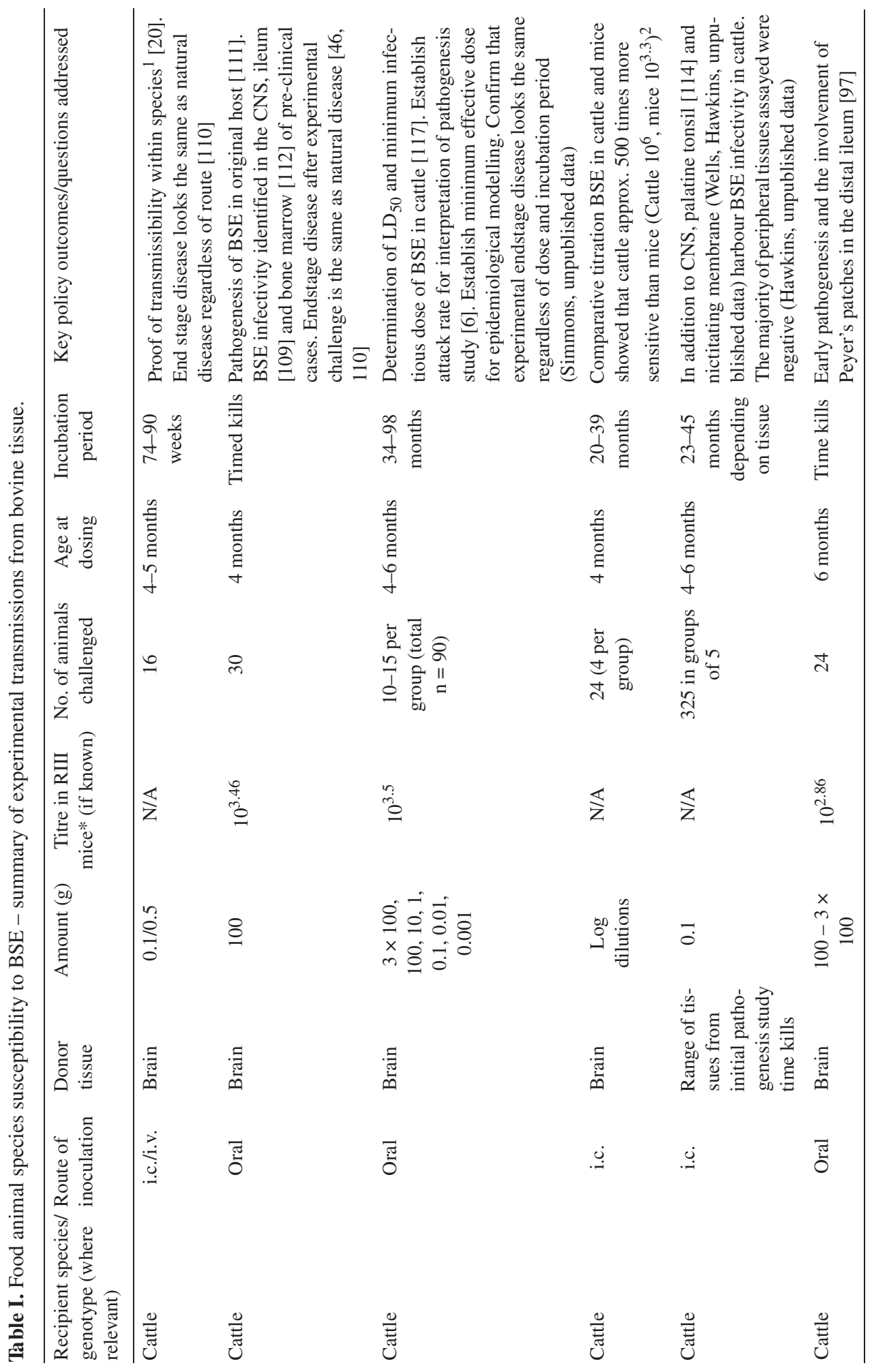




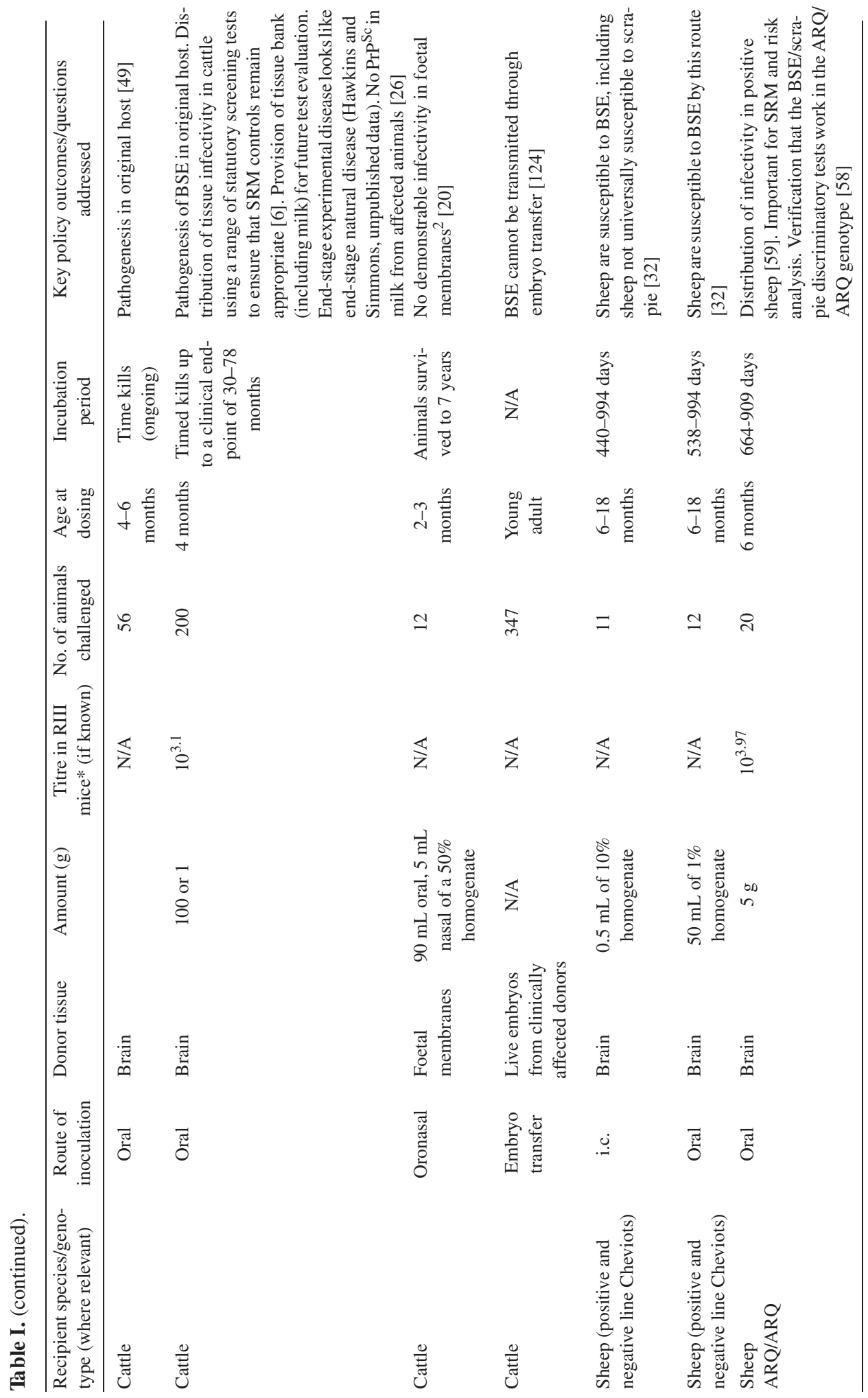




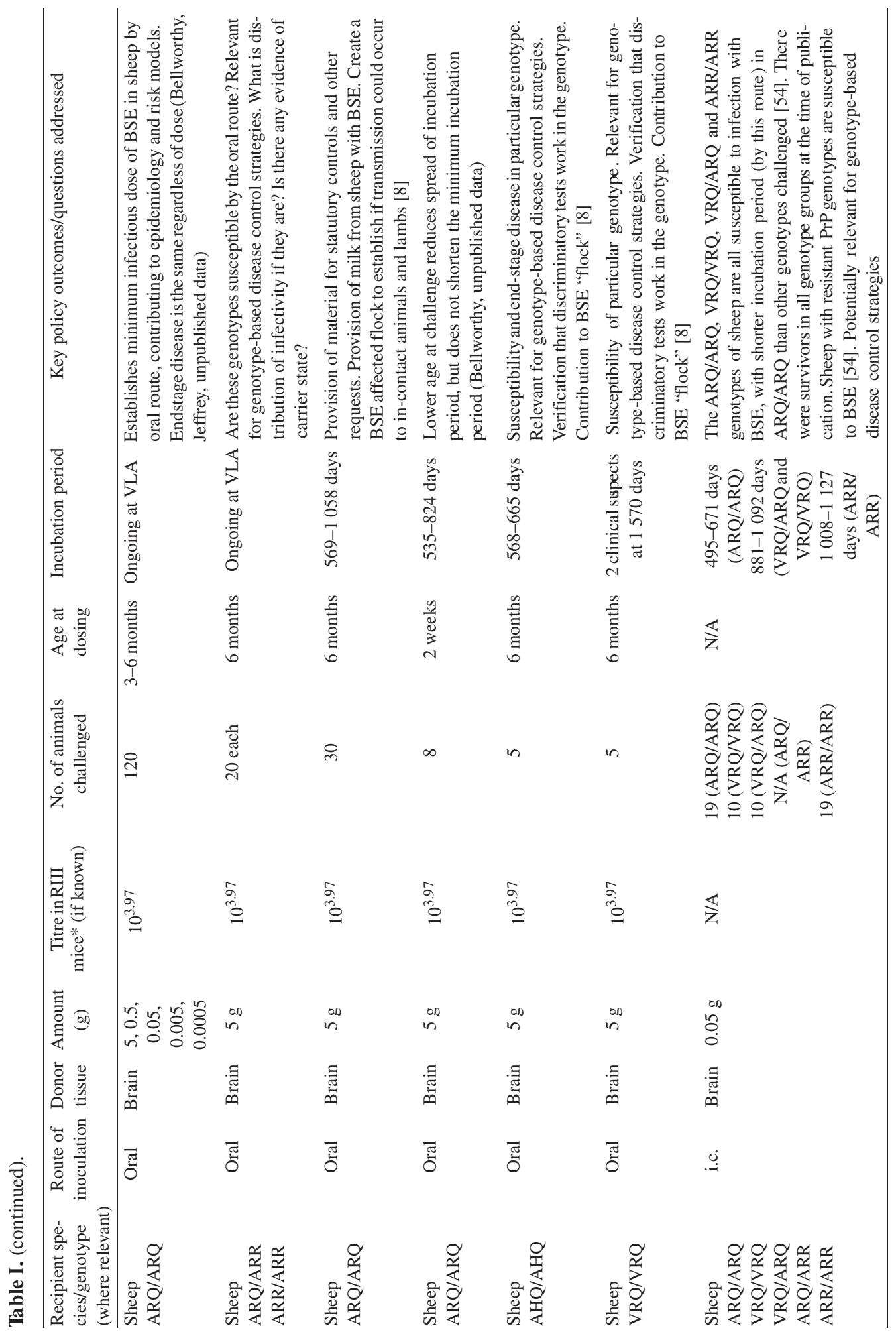




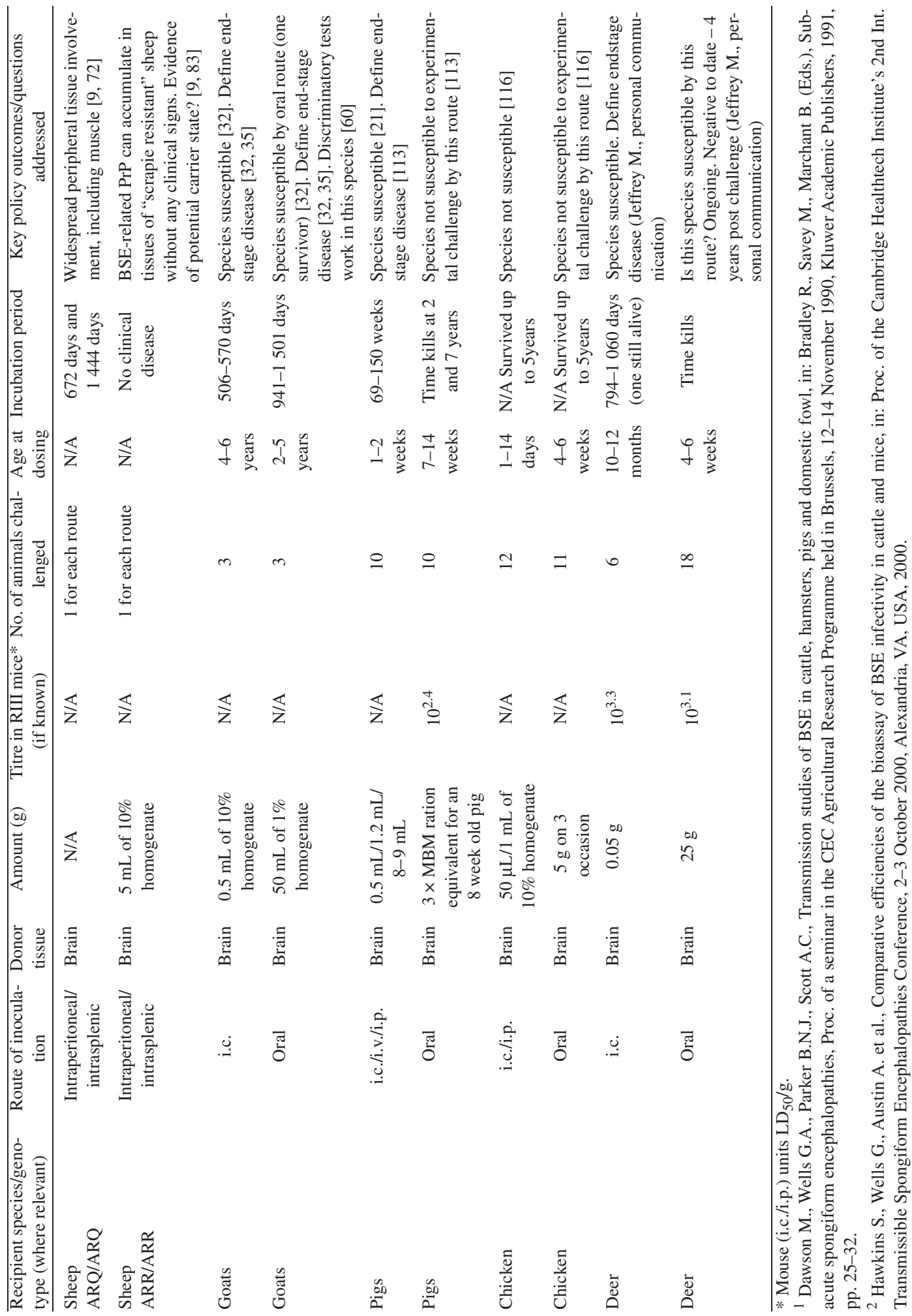


For BSE, epidemiological studies indicated that the oral ingestion of food contaminated with infected ruminant-derived protein, in the form of meat and bone meal (MBM), by cattle was likely to be a major route of transmission $[118,120]$. Oral challenge studies showed that transmission of BSE was possible to sheep, goats and cattle by this route $[32,59,111]$ and with very low challenge doses [117]. Transmission to pigs or chickens however was not achieved by this experimental route [113, 116].

One difficulty that arises with transmission experiments is the interpretation of a negative result; does it mean that transmission does not occur, or just that in this particular scenario it hasn't? The latter then raises questions as to why it may not have occurred. Is it the dose, route, or are there other factors involved such as species barriers or genetic influences? Given that BSE could be transmitted to pigs by the i.c. route, the absence of BSE transmission to pigs by the oral route indicated that there may be an effective species barrier, but a particular confounding factor in this type of study is that the infectious "dose" of any challenge inoculum is difficult to establish objectively. In most cases, inoculum titre (if known) is quoted as mouse LD50/g, using conventional inbred mice. However, we know that different hosts are differently susceptible [88] and that some TSE isolates do not transmit to particular species (including mice). Any experimentallyestablished titre is inevitably relative, and not necessarily informative for the recipient species in a particular experiment. Attempts to determine $\mathrm{PrP}^{\mathrm{Sc}}$ concentration biochemically as a measure of titre are also limited by the assumption that $\mathrm{PrP}^{\mathrm{Sc}}$ is an accurate and quantifiable marker for infectivity.

Conversely, a positive result in a transmission experiment only means that transmission can occur, not that it does in field conditions. It also leads to further questions. One is the relevance of such experiments to the field situation. There are a number of fundamental differences between natural exposure and experimental studies which should not be overlooked when comparing disease models with field cases. In natural disease, the inci- dence of TSE can be low but in experimental disease the aim is to achieve $100 \%$ morbidity, especially if the study contains a time-kill element. Very high doses can be given orally and such experimental exposures result in much higher attack rates than are observed naturally [117]. Time-kill approaches can then be used to study the disease pathogenesis in an experimental model, although it is not known what effect dose may have on pathogenesis. It is reassuring, therefore, that the end-stage disease resulting from such experimental exposure of cattle with BSE is virtually indistinguishable from natural cases in all but morbidity [46].

This experimental approach also assumes an oral route of transmission in the field, which is a reasonable assumption for BSE, given the clear epidemiological links with contaminated feed. However, the infectious material in feed has been subjected to a range of manufacturing processes and heat treatments in the course of MBM production, and experimental studies often use "neat" brain material (untreated) to achieve the best morbidity, since rendering has been shown to reduce titre [27, 91, 94-96]. The possible effects of rendering on the basic biological properties of any given TSE strain are very difficult to define, and almost impossible to control for in any experimental design.

It has also been suggested that age at exposure can affect susceptibility [5], but most experimental designs have focussed on a restricted range of ages at challenge from a logistical point of view.

None of these factors negates the data emerging from such experimental studies, as the studies provide a starting point. Once transmission has been achieved, further experimental protocols can be used to investigate aspects such as minimum effective doses [117], and inoculum can be treated to mimic more closely what is occurring in the field [95]. Data derived from transmission experiments can also be used in risk analyses and mathematical models, both of which may be used to inform the development of appropriate control strategies for TSE in animals, and thus to protect public and animal health. Further studies can also be implemented, as they were with $\mathrm{BSE}$, to investigate hypotheses of the origin of 
the disease (for example scrapie to cattle [66]), but countless variables prevent this approach from being comprehensive.

\subsubsection{Natural transmission}

With experimental confirmation that transmission is possible by a particular route, further investigation of the contribution of that route to natural transmission is vital.

For BSE it was clear that the principal driver of the epidemic was the feeding of contaminated MBM [120] - once relevant control measures were introduced the epidemic in Great Britain began to decline $[50,122]$ - but it was not initially known whether the disease could be sustained within an affected population by other natural or management means.

Evidence from a cohort study did not rule out the possibility of a maternal component to transmission [121]. The risk of developing BSE was slightly increased by being born to a dam approaching the clinical phase of the disease. Whether it represented genetic susceptibility, transmission or a combination of the two could not be determined. However, mathematical modelling indicated that if maternal transmission did occur, then it was highly unlikely to be at a rate that could sustain an epidemic [23]. The route through which such exposure might take place, whether it was due to true vertical transmission, or horizontal transmission through close contact also could not be established from the cohort study. A long-term large-scale experimental study to investigate the possibility of vertical transmission indicated that, "when appropriate sanitary protocols" were followed, "embryos derived from BSE-affected cattle did not transmit the disease" [124].

Ultimately for BSE in cattle the relative importance of the role of feed contaminated with infected MBM was confirmed, and the relative absence of evidence for maternal transmission [23] has enabled effective disease control interventions to be implemented.

\section{BSE IN SMALL RUMINANTS}

The positive results of oral transmission experiments to sheep and goats $[32,59]$, and the identification of a single natural case of BSE in a French goat [24] have, however, raised a new challenge: that of BSE in small ruminants. For Great Britain, this raised a concern about the national sheep population. With, hopefully, no naturally-occurring disease to study there remain only three alternatives.

Firstly, to set up small-scale animal experiments (as previously described) to investigate potential routes and mechanisms of transmission; secondly to set-up larger-scale natural transmission investigations, such as an experimental sheep flock; and thirdly, to find an alternative natural disease model that can be studied in the field.

\subsection{Direct experimental exposure}

Transmission of BSE in small ruminants by blood transfusion has been studied by the first method. Whilst experimental BSE can be transmitted by whole blood transfusion [53], this probably has more relevance in the establishment of a precedent for the protection of public health in the context of humanto-human transmission [1], rather than as a potential iatrogenic route in small ruminants.

\subsection{Natural transmission experiments}

The second method (the experimental sheep flock) has been used by both the Veterinary Laboratories Agency (VLA) and the Institute for Animal Health Neuropathogenesis Unit (NPU) in Edinburgh. The VLA has an experimental BSE-in-sheep flock in which lambs born to ewes that were orally dosed with $5 \mathrm{~g}$ of BSE-positive cattle brain have succumbed to clinical disease [8]. The age at onset for these lambs ranged from 654 to 968 days old. In all cases the birth of the lambs occurred within a few months prior to the onset of clinical disease in their dams. Thus we have evidence of natural transmission of BSE from sheep to sheep, albeit in experimental circumstances. Whether this represents true vertical or perinatal infection cannot be ascertained from this study. A similar but slightly different NPU study [36] did not result in transmission, however it could not be statistically ruled out. 


\subsection{Alternative disease models}

The third method, to find an alternative natural disease model that can be studied in the field, is more problematic. Studies of the natural transmission of the only known naturally-occurring TSE of small ruminants, scrapie, might provide a model for BSE in sheep, should it occur under field conditions. Both scrapie and experimental BSE in sheep have similar clinical signs and they have similar diffuse tissue distributions of $\mathrm{PrP}^{\mathrm{Sc}}$ [34, $35,59,115]$. If natural ovine BSE is similar to experimental ovine BSE, then ovine BSE may potentially behave in a similar manner to scrapie as far as routes and mechanisms of transmission are concerned.

\subsubsection{Scrapie}

This is the most extensively studied TSE model. Several institutions have established, maintained and recorded naturally infected flocks of sheep in order to study various aspects of scrapie, including its transmission. These include the INRA Langlade flock of Romanov sheep, various Institute for Animal Health flocks and the VLA scrapie-affected flock.

Analyses of data collected over more than a decade from the first of these have provided epidemiological evidence for both a maternal and lateral component of transmission $[22,99]$. Higher relative risks of clinical scrapie were observed associated with lambing periods. There was also a reduced risk of clinical scrapie in artificially-reared lambs from healthy dams, and an increased risk in maternally-reared lambs from scrapie-affected dams. They proposed that transmission may occur within the first $24 \mathrm{~h}$ of life with additional risk for those that then continue to share the maternal environment (all lambs remained on their dams for the first intake of colostrum and then for $24 \mathrm{~h}$ ).

The Institute for Animal Health flocks have established that, despite earlier contradictory findings [30, 31, 33], true vertical transmission of ovine scrapie (via the germ-line or in utero) is improbable [36, 37]. A scrapie-free flock has been established by embryo-transfer (ET) from one with a long-standing scrapie problem. The ET-derived flock has remained scrapie-free since its establishment in 1996, even though it has a similar $\operatorname{Pr} P$ genetic profile to the original flock. Of interest to mechanisms of horizontal/lateral transmission is the fact that the "clean" flock was established and maintained in a scrapie naïve environment; a parallel ET-derived flock that was maintained in close proximity to, but separate from, the original scrapie-affected flock did experience clinical scrapie cases [37]. Lateral transmission has also been shown to occur in the absence of lambing [38].

In the VLA flock it has been shown that lateral transmission occurs [84] and that exposure to a contaminated environment only is sufficient to produce disease (Dexter, Tongue, Bellworthy, unpublished data).

These flocks are managed in a way that maintains high frequencies of sheep with PrP genotypes at high risk of developing clinical disease. Thus with a high incidence of clinical disease and high infectious load, they also provide controlled environments in which to study the pathogenesis of naturally acquired disease. They effectively counter the difficulties of studying a disease that occurs at a low flock-level incidence, however it must be recognised that whilst they provide evidence for routes and mechanisms of natural transmission and estimates of transmission parameters, they are probably not representative of any but the most heavily affected (worstcase scenario) commercial flocks. They are also limited in the range of breeds present, and (potentially) in the number of different scrapie isolates/strains present. These flocks may mimic natural exposure, but at a level that no commercial flock-owner would be able to tolerate and remain as an economically viable unit. Because of this the relative importance of different components of transmission may vary in commercial field flocks and therefore intervention measures may have different outcomes. These institutionalised research flocks, therefore, act as an important bridge between the artificial exposure - natural route transmission experiments - and the true field situation.

A variety of experimental studies using the approaches outlined above have provided 
evidence for possible routes of transmission of scrapie. $\mathrm{PrP}^{\mathrm{Sc}}$ has been found in tissues that could be involved in the natural dissemination of the infectious agent i.e., routes that could lead to exit of the infectious agent from the animal, and result in either environmental contamination or direct transmission. These tissues include the lympho-reticular system of the gut [40, 103, 115], chronically inflamed mammary tissue associated with lymphocyctic mastitis [73], kidney tissue [90], salivary glands [104], nictitating membrane [77], and placentae [2, 81, 101].

For the majority of these tissues, evidence of infectivity or the presence of $\mathrm{PrP}^{\mathrm{Sc}}$ in associated secretions and excretions is still elusive for scrapie in small ruminants. The exception is blood [55]. Although experimental blood transfusions have resulted in clinical scrapie [55], just as with BSE, it is unlikely to play a major role: blood transfusions are not regular occurrences in sheep veterinary practice.

On the other hand, not only has $\operatorname{PrP}^{\mathrm{Sc}}$ and infectivity been demonstrated in placentae [3, $81,101]$, but it has also been shown to produce clinical scrapie when administered orally to sheep $[78,79]$. This was proposed by the authors as a mechanism for lateral transmission from ewe to ewe at lambing time. Placenta has also been cited as a possible explanation for some of the epidemiological findings thought to be associated with mechanisms of maternal transmission [74], although much of the epidemiological evidence may also be interpreted as a contribution to transmission via the lateral route, especially that of environmental contamination. For example, there are reduced odds of ever becoming a scrapieaffected flock if the flock sometimes lambs in different places, compared to those flocks that always lamb in the same place [74]; there is decreased risk of disease associated with lambing in individual pens [75], and there were increased odds for scrapie-positive status of a flock that was found to be associated with failure to remove placenta from bedding along with its disposal in compost.

Epidemiological cross-sectional [74, 75] and case-control studies $[47,51,80]$ have provided supporting evidence for the role of var- ious allied management practices in the transmission of scrapie in the field. So far they lack the consistency and specifics necessary for the development of appropriate intervention measures. The scrapie literature does however illustrate how the different types of investigations into aspects of transmission, and the different disciplines, are complementary. Experimental studies of transmission routes and epidemiological studies of risk factors are intrinsically linked in a positive feedback loop, each informing the other.

\subsubsection{Chronic wasting disease}

The other naturally occurring TSE, CWD of deer is probably less relevant as a model for BSE in small ruminants, has been recently reviewed elsewhere [123] and is covered by Sigurdson in this special issue [89].

\subsubsection{Other disease models}

Host-specific experimental studies in large animals are expensive and do take time to produce results. The former means that they are difficult to fund. The latter means that they may have to be run in parallel with other experiments, often with more start-up assumptions than desirable, rather than in a logical step-wise order following on from previous findings. They are, however, of paramount importance. They provide an opportunity to study the disease in the original host species; they can be comparable across studies, if standardised protocols are used, and they eliminate the noise of variability, the difficulties of loss to follow-up and the potential biases that are experienced with epidemiological studies. To counter the time and resource limitations, other models have been sought.

The role of hamsters, mice, the burgeoning range of murine transgenes and other models such as voles is a large subject in its own right, and is covered by Groschup and Buschmann in this special issue [44] and elsewhere [28, 43]. In the past such models have been useful $[12,13]$, but they also have limitations. For example, laboratory wild-type mice cannot replace the original donor species due to the species-transmission barrier and to their different biology and physiology compared 
to ruminants. The former has been addressed with the advent of transgenic mice, the latter is insurmountable. Even these do not replicate reality, and the interpretation and extrapolation of any results back to the donor/host-species needs to be a considered, objective process. For example, data from different transgenic mouse lines are not directly comparable, even between lines which have a common transgene $[16,105]$.

\section{PUBLIC HEALTH}

The ultimate question of whether a TSE has implications for public health - i.e. is transmissible to man - is difficult to address in the absence of transmission experiments on people. The most appropriate alternative is to use non-human primates $[48,67,68,70]$ which have indicated that BSE transmits with a endstage disease indistinguishable from variant Creutzfeldt-Jacob disease (vCJD). However these experiments are limited by ethical constraints. Here the development of transgenic mice has been of prospective value, but at the same time, can be misleading. For example, mice with a single copy of the human $\operatorname{PrP}$ gene were not susceptible experimentally to BSE [10] while at the same time, epidemiological and strain-typing studies were producing a very strong body of circumstantial evidence that vCJD was a consequence of BSE infection in man. The inevitable limitation of such transgenic mice is that only one human gene is present in the model, and disease susceptibility and incubation period are inevitably multi-factorial. Transgenic mouse models which overexpress human $\operatorname{Pr} P$ are also available, and they are highly susceptible to BSE [7, 15, 65, 106] but these may not be a true indicator of susceptibility in humans. Detailed discussion of these models is outwith the scope of this paper and is covered in detail by Groschup and Buschmann in this special issue [44].

\section{REMAINING CHALLENGES}

Many challenges remain even when a spongiform encephalopathy has been identified as transmissible, and when routes and mechanisms have been proposed.
What are the effects of repeated low dose exposure? What happens when there is intercurrent disease? How do $\operatorname{Pr} P$ genetics influence the transmission process? Is any apparent reduction in susceptibility actually an effect of incubation period prolongation to beyond the natural lifespan? What is the implication of carrier state/subclinical disease for disease control and health? How can we detect animals in the early stage of disease incubation a phase "silent" to current investigative tools?

For BSE and scrapie some of these questions have been addressed partially [39, 42, $45,49,56,61]$. It is possible that for novel TSE many of these questions will remain unanswered or unpursued, except by the most determined of researchers after the funding, stimulated by the public health and political aspects of BSE and vCJD, has dwindled.

Perhaps the greatest conundrum for researchers faced with a new TSE in a species, or a TSE in a species in which it has not previously been described, is whether it is "new", or merely "newly observed". This is a particular issue for BSE, should it be found in the sheep population. With much speculation over the years that scrapie could be the origin of BSE, it might not be too surprising if a detailed study of scrapie isolates revealed one with BSE-like characteristics. A number of studies in the UK and elsewhere $[19,66,82]$ have taken a direct approach to this question by looking at the experimental phenotype in cattle experimentally challenged with scrapie isolates, but the diversity of scrapie isolates precludes this approach being exhaustive.

Given that no one type of study can provide all the details or all the answers required, and because of the constraints implicit in each type of study, it is important that researchers respect and integrate the work from other areas, are rigorous, do not overestimate their findings despite various pressures to do so, and are honest: both in the presentation of their findings and in the value of the outcomes. Some of those interested in pure science may disparage studies that they deem to be of low scientific merit, but which are actually of high value to those involved in policy and decision-making: equally some work of high scientific merit may 
be extremely interesting in its own right, but not actually necessary to advance disease control and protect public health.

\section{CONCLUSION}

The approaches to the investigation of the transmission of BSE and scrapie, outlined above, differ only slightly. Those differences are due to the nature of the two diseases. BSE was a novel spongiform encephalopathy, in a hitherto unaffected species, that had characteristics of a point source epidemic, with an agent that could have been incorporated into a wide variety of feedstuffs and iatrogenically administered to naïve populations, and there was early evidence that it was not restricted to bovines. It was vital to establish, albeit experimentally, which other species might be affected, and whether the epidemic could be maintained by natural transmission, if the source was removed. In contrast, scrapie has been endemic throughout Great Britain for centuries, is maintained naturally (even if we don't know exactly how) and has a known host range. The principles, process and integration of evidence from different types of studies, however, are similar for both of these TSE and can be applied to any emerging or suspected spongiform encephalopathy.

\section{REFERENCES}

[1] Aguzzi A., Glatzel M., vCJD tissue distribution and transmission by transfusion - a worst case scenario coming true?, Lancet (2004) 363:411-412.

[2] Andréoletti O., Lacroux C., Chabert A., Monnereau L., Tabouret G., Lantier F., et al., $\mathrm{PrP}^{\mathrm{Sc}}$ accumulation in placentas of ewes exposed to natural scrapie: influence of foetal PrP genotype and effect on ewe-to-lamb transmission, J. Gen. Virol. (2002) 83:2607-2616.

[3] Anonymous, Encyclopaedic word dictionary, Hanks P. (Ed.), Paul Hamlyn, London, New York, Sydney, Toronto, 1971.

[4] Anonymous, The concise Oxford English dictionary of current English, 9th ed., Thomson D. (Ed.), Oxford university press, 1995.

[5] Arnold M., Wilesmith J.W., Estimation of the agedependent risk of infection to BSE of dairy cattle in Great Britain, Prev. Vet. Med. (2004) 66:35-47.

[6] Arnold M.E., Ryan J.B.M., Konold T., Simmons M.M., Spencer Y.I., Wear A., et al., Estimating the temporal relationship between $\operatorname{PrP}^{\mathrm{Sc}}$ detection and incubation period in experimental bovine spongiform encephalopathy (BSE) of cattle, J. Gen. Virol. (2007) 88:3198-3208.

[7] Asante E.A., Linehan J.M., Desbruslais M., Joiner S., Gowland I., Wood A.L., et al., BSE prions propagate as either variant CJD-like or sporadic CJD-like prion strains in transgenic mice expressing human prion protein, EMBO J. (2002) 21:6358-6366.

[8] Bellworthy S.J., Dexter G., Stack M., Chaplin M., Hawkins S.A.C., Simmons M.M., et al., Natural transmission of BSE between sheep within an experimental flock, Vet. Rec. (2005) 157:206.

[9] Bencsik A., Baron T., Bovine spongiform encephalopathy agent in a prion protein $(\operatorname{PrP})^{\mathrm{ARR} / A R R}$ genotype sheep after peripheral challenge: complete immunohistochemical analysis of disease-associated PrP and transmission studies to ovine-transgenic mice, J. Infect. Dis. (2007) 195:989-996.

[10] Bishop M.T., Hart P., Aitchison L., Baybutt H.N., Plinston C., Thomson V., et al., Predicting susceptibility and incubation time of human-to-human transmission of vCJD, Lancet Neurol. (2006) 5:393-398.

[11] Blood D.C., Studdert V.P., Baillière's comprehensive veterinary dictionary, Baillière Tindall, London, UK, 1988.

[12] Bruce M.E., Strain typing studies of scrapie and BSE, in: Baker H.F., Ridley R.M. (Eds.), Methods in molecular medicine - Prion diseases, Humana Press, Totowa, USA, 1996, pp. 223-236.

[13] Bruce M.E., Boyle A., Cousens S., McConnell I., Foster J., Goldmann W., Fraser H., Strain characterization of natural sheep scrapie and comparison with BSE, J. Gen. Virol. (2002) 83:695-704.

[14] Bundza A., Charlton K.M., Comparison of spongiform lesions in experimental scrapie and rabies in skunks, Acta Neuropathol. (1988) 76:275-280.

[15] Collinge J., Palmer M.S., Sidle K.C., Hill A.F., Gowland I., Meads J., et al., Unaltered susceptibility to BSE in transgenic mice expressing human prion protein, Nature (1995) 378: 779-783.

[16] Cordier C., Bencsik A., Philippe S., Betemps D., Ronzon F., Calavas D., Crozet C., Baron T., Transmission and characterization of bovine spongiform encephalopathy sources in two ovine transgenic mouse lines (TgOvPrP4 and TgOvPrP59), J. Gen. Virol. (2006) 87:3763-3771.

[17] Cuillé J., Chelle P.L., La maladie dite "tremblante" du mouton; est-elle inoculable ?, C. R. Acad. Sci. Paris (1936) 203:1552-1554.

[18] Cuillé J., Chelle P.L., La maladie dite "tremblante" du mouton est bien inoculable, C. R. Acad. Sci. Paris (1938) 206:78-79.

[19] Cutlip R.C., Miller J.M., Race R.E., Jenny A.L., Katz J.B., Lehmkuhl H.D., et al., Intracerebral transmission of scrapie to cattle, J. Infect. Dis. (1994) 169:814-820.

[20] Dawson M., Wells G.A., Parker B.N., Preliminary evidence of the experimental transmissibility of bovine 
spongiform encephalopathy to cattle, Vet. Rec. (1990) 126:112-113.

[21] Dawson M., Wells G.A., Parker B.N., Scott A.C., Primary parenteral transmission of bovine spongiform encephalopathy to the pig, Vet. Rec. (1990) 127:338.

[22] Diaz C., Vitezica Z.G., Rupp R., Andréoletti O., Elsen J.M., Polygenic variation and transmission factors involved in the resistance/susceptibility to scrapie in a Romanov flock, J. Gen. Virol. (2005) 86:849-857.

[23] Donnelly C.A., Ferguson N.M., Ghani A.C., Anderson R.M., Implications of BSE infection screening data for the scale of the British BSE epidemic and current European infection levels, Proc. Biol. Sci. (2002) 269:2179-2190.

[24] Eloit M., Adjou K., Coulpier M., Fontaine J.J., Hamel R., Lilin T. et al., BSE agent signatures in a goat, Vet. Rec. (2005) 156:523-524.

[25] Elsen J.M., Amigues Y., Schelcher F., Ducrocq V., Andréoletti A., Eychenne F., et al., Genetic susceptibility and transmission factors in scrapie: detailed analysis of an epidemic in a closed flock of Romanov, Arch. Virol. (1999) 144:431-445.

[26] Everest S.J., Thorne L.T., Hawthorn J.A., Jenkins R., Hammersley C., Ramsay A.M., et al., No abnormal prion protein detected in the milk of cattle infected with the bovine spongiform encephalopathy agent, J. Gen. Virol. (2006) 87:2433-2441.

[27] Fernie K., Steele P.J., Taylor D.M., Somerville R.A., Comparative studies on the thermostability of five strains of transmissible-spongiformencephalopathy agent, Biotechnol. Appl. Biochem. (2007) 47:175-183.

[28] Flechsig E., Hegyi I., Raeber A.J., Cozzio A., Aguzzi A., Weissmann C., Knockouts and transgenic mice in prion research, in: Hörnlimann B., Riesner D., Kretzschmar H. (Eds.), Prions in humans and animals, de Gruyter, Berlin, Germany, 2007, pp. 134-150.

[29] Foley G.L., Zachary J.F., Rabies-induced spongiform change and encephalitis in a heifer, Vet. Pathol. (1995) 32:309-311.

[30] Foote W.C., Clark W., Maciulis A., Call J.W., Hourrigan J., Evans R.C. et al., Prevention of scrapie transmission in sheep using embryo transfer, Am. J. Vet. Res. (1993) 54:1863-1868.

[31] Foster J.D., McKelvey W.A., Mylne M.J., Williams A., Hunter N., Hope J., Fraser H., Studies on maternal transmission of scrapie in sheep by embryo transfer, Vet. Rec. (1992) 130:341-343.

[32] Foster J.D., Hope J., Fraser H., Transmission of bovine spongiform encephalopathy to sheep and goats, Vet. Rec. (1993) 133:339-341.

[33] Foster J.D., Hunter N., Williams A., Mylne M.J., McKelvey W.A., Hope J., Fraser H., Bostock C., Observations on the transmission of scrapie in experiments using embryo transfer, Vet. Rec. (1996) 138:559-562.

[34] Foster J.D., Parnham D.W., Hunter N., Bruce M., Distribution of the prion protein in sheep terminally affected with BSE following experimental oral transmission, J. Gen. Virol. (2001) 82:2319-2326.

[35] Foster J.D., Parnham D., Chong A., Goldmann W., Hunter N., Clinical signs, histopathology and genetics of experimental transmission of BSE and natural scrapie to sheep and goats, Vet. Rec. (2001) 148:165171.

[36] Foster J.D., Goldmann W., McKenzie C., Smith A., Parnham D.W., Hunter N., Maternal transmission studies of BSE in sheep, J. Gen. Virol. (2004). 85:3159-3163.

[37] Foster J., McKenzie C., Parnham D., Drummond D., Goldmann W., Stevenson E., Hunter N., Derivation of a scrapie-free sheep flock from the progeny of a flock affected by scrapie, Vet. Rec. (2006) 159:42-45.

[38] Foster J., McKenzie C., Parnham D., Drummond D., Chong A., Goldmann W., Hunter N., Lateral transmission of natural scrapie to scrapie-free New Zealand sheep placed in an endemically infected UK flock, Vet. Rec. (2006) 159:633-634.

[39] Goldmann W., Houston F., Stewart P., Perucchini M., Foster J., Hunter N., Ovine prion protein variant $\mathrm{A}(136) \mathrm{R}(154) \mathrm{L}(168) \mathrm{Q}(171)$ increases resistance to experimental challenge with bovine spongiform encephalopathy agent, J. Gen. Virol. (2006) 87:37413745.

[40] González L., Dagleish M.P., Bellworthy S.J., Sisó S., Stack M.J., Chaplin M.J., et al., Postmortem diagnosis of preclinical and clinical scrapie in sheep by the detection of disease-associated PrP in their rectal mucosa, Vet. Rec. (2006) 158:325-331.

[41] Gordon W.S., Advances in veterinary research. Louping-ill, tick borne fever and scrapie, Vet. Rec. (1946) 58:516-520.

[42] Gravenor M.B., Stallard N., Curnow R., McLean A.R., Repeated challenge with prion disease: the risk of infection and impact on incubation period, Proc. Natl. Acad. Sci. USA (2003) 100:10960-10965.

[43] Groschup M.H., Geissen M., Buschmann A., The experimental transmissibility of prions and infectivity distribution in the body, in: Hörnlimann B., Riesner D., Kretzschmar H. (Eds.), Prions in humans and animals, de Gruyter, Berlin, Germany, 2007, pp. 473-478.

[44] Groschup M.H., Buschmann A., Rodent models for prion diseases, Vet. Res. (2008) 39:32.

[45] Gruner L., Elsen J.M., Vu Tein Khang J., Eychenne F., Caritez J.C., Jacquiet P., et al., Nematode parasites and scrapie: experiments in sheep and mice, Parasitol. Res. (2004) 93:493-498.

[46] Hawkins S.A.C., Wells G.A.H., Simmons M.M., Blamire I.W.H., Meek S.C., Harris P., The topographic distribution pattern of vacuolation in the central nervous system of cattle infected orally with bovine spongiform encephalopathy, Bovine Practitioner (1997) 31.2:73-76.

[47] Healy A.M., Hannon D., Morgan K.L., Weavers E., Collins J.D., Doherty M.L., A paired case-control study of risk factors for scrapie in Irish sheep flocks, Prev. Vet. Med. (2004) 64:73-83. 
[48] Herzog C., Salès N., Etchegaray N., Charbonnier A., Freire S., Dormont D., et al., Tissue distribution of bovine spongiform encephalopathy agent in primates after intravenous or oral infection, Lancet (2004) 363:422-428.

[49] Hoffmann C., Ziegler U., Buschmann A., Weber A., Kupfer L., Oelschlegel A., Hammerschmidt B., Groschup M.H., Prions spread via the autonomic nervous system from the gut to the central nervous system in catle incubating bovine spongiform encephalopathy, J. Gen. Virol. (2007) 88:1048-1055.

[50] Hoinville L.J., Decline in the incidence of BSE in cattle born after the introduction of the "feed ban", Vet. Rec. (1994) 134:274-275.

[51] Hopp P., Ulvund M.J., Jarp J., A case-control study on scrapie in Norwegian sheep flocks, Prev. Vet. Med. (2001) 51:183-198.

[52] Hornlimann B., Riesner D., Kretzschmar H. (Eds.), Prions in humans and animals, de Gruyter Berlin, New York, 2007.

[53] Houston F., Foster J.D., Chong A., Hunter N., Bostock C.J., Transmission of BSE by blood transfusion in sheep, Lancet (2000) 356:999-1000.

[54] Houston F., Goldmann W., Chong A., Jeffrey M., González L., Foster J., et al., Prion diseases: BSE in sheep bred for resistance to infection, Nature (2003) 423:498.

[55] Hunter N., Foster J., Chong A., McCutcheon S., Parnham D., Eaton S., et al., Transmission of prion diseases by blood transfusion, J. Gen. Virol. (2002) 83:2897-2905.

[56] Jackman R., Everest D.J., Schmerr M.J., Khawaja M., Keep P., Docherty J., Evaluation of a preclinical blood test for scrapie in sheep using immunocapillary electrophoresis, J. AOAC Int. (2006) 89:720-727.

[57] Jeffrey M., Wells G.A.H., Spongiform encephalopathy in a nyala (Tragelaphus angasi), Vet. Pathol. (1988) 25:398-399.

[58] Jeffrey M., Martin S., Gonzalez L., Ryder S.J., Bellworthy S.J., Jackman R., Differential diagnosis of infections with the bovine spongiform encephalopathy (BSE) and scrapie agents in sheep, J. Comp. Pathol. (2001) 125:271-284.

[59] Jeffrey M., Ryder S., Martin S., Hawkins S.A., Terry L.M., Berthelin-Baker C., Bellworthy S.J., Oral inoculation of sheep with the agent of bovine spongiform encephalopathy (BSE). 1. Onset and distribution of disease-specific PrP accumulation in brain and viscera, J. Comp. Pathol. (2001) 124:280-289.

[60] Jeffrey M., Martin S., Gonzalez L., Foster J., Langeveld J.P., van Zijderveld F.G., et al., Immunohistochemical features of $\operatorname{PrP}(d)$ accumulation in natural and experimental goat transmissible spongiform encephalopathies, J. Comp. Pathol. (2006) 134:171-181.

[61] Kao R.R., Houston F., Baylis M., Chihota C.M., Goldmann W., Gravenor M.B., et al., Epidemiological implications of the susceptibility to BSE of putatively resistant sheep, J. Gen. Virol. (2003) 84:3503-3512.
[62] Kelly D.F., Gaskell C.J., Spongy degeneration of the central nervous system in kittens, Acta Neuropathol. (1976) 35:151-158.

[63] Kinney H.C., Sidman R.L., Pathology of the spongiform encephalopathy in the gray tremor mutant mouse, J. Neuropathol. Exp. Neurol. (1986) 45:108126.

[64] Kirkwood J.K., Cunningham A.A., Epidemiological observations on spongiform encephalopathies in captive wild animals in the British Isles, Vet. Rec. (1994) 135:296-303.

[65] Kong Q., Huang S., Zou W., Vanegas D., Wang M., Wu D., et al., Chronic wasting disease of elk: transmissibility to humans examined by transgenic mouse models, J. Neurosci. (2005) 25:7944-7949.

[66] Konold T., Ryder S.J., Lee Y.H., Stack M.J., Horrocks C., Green R., et al., Different prion disease phenotypes result from inoculation of cattle with two temporally separated sources of sheep scrapie from Great Britain, BMC Vet. Res. (2006) 2:31.

[67] Lasmézas C.I., Comoy E., Hawkins S., Herzog C., Mouthon F., Konold T., et al., Risk of oral infection with bovine spongiform encephalopathy agent in primates, Lancet (2005) 365:781-783.

[68] Lasmézas C.I., Deslys J.P., Demaimay R., Adjou K.T., Lamoury F., Dormont D., et al., BSE transmission to macaques, Nature (1996) 381:743-744.

[69] Lasmezas C.I., Deslys J.P., Robain O., Jaegly A., Béringue V., Peyrin J.M., et al., Transmission of the BSE agent to mice in the absence of detectable abnormal prion protein, Science (1997) 275:402-405.

[70] Lasmézas C.I., Fournier J.G., Nouvel V., Boe H., Marcé D., Lamoury F., et al., Adaptation of the bovine spongiform encephalopathy agent to primates and comparison with Creutzfeldt-Jakob disease: implications for human health, Proc. Natl. Acad. Sci. USA (2001) 98:4142-4147.

[71] Last J.M., A Dictionary of Epidemiology, 2nd ed., Oxford University Press, New York, USA, 1988.

[72] Lezmi S., Ronzon F., Bencsik A., Bedin A., Clavas D., Richard Y., et al., $\operatorname{PrP}^{\mathrm{d}}$ accumulation in organs of ARQ/ARQ sheep experimentally infected with BSE by peripheral routes, Acta Biochim. Pol. (2006) 53:399-405.

[73] Ligios C., Sigurdson C.J., Santucciu C., Carcassola G., Manco G., Basagni M., et al., $\mathrm{PrP}^{\mathrm{Sc}}$ in mammary glands of sheep affected by scrapie and mastitis, Nat. Med. (2005) 11:1137-1138.

[74] McIntyre M., Gubbins S., Sivam S.K., Baylis M., Flock-level risk factors for scrapie in Great Britain: analysis of a 2002 anonymous postal survey, BMC Vet. Res. (2006) 2:25.

[75] McLean A.R., Hoek A., Hoinville L.J., Gravenor M.B., Scrapie transmission in Britain: a recipe for a mathematical model, Proc. Biol. Sci. (1999) 266:2531-2538.

[76] Office Internationale Epizootie, Bovine spongiform encephalopathy, in: OIE manual of diagnostic 
tests and vaccines for terrestrial animals, 5th ed., 2004, pp. 549-569.

[77] O'Rourke K.I., Baszler T.V., Besser T.E., Miller J.M., Cutlip R.C., Wells G.A., et al., Preclinical diagnosis of scrapie by immunohistochemistry of third eyelid lymphoid tissue, J. Clin. Microbiol. (2000) 38:3254-3259.

[78] Pattison I.H., Hoare M.N., Jebbett J.N., Watson W.A., Spread of scrapie to sheep and goats by oral dosing with foetal membranes from scrapie-affected sheep, Vet. Rec. (1972) 90:465-468.

[79] Pattison I.H., Hoare M.N., Jebbett J.N., Watson W.A., Further observations on the production of scrapie in sheep by oral dosing with foetal membranes from scrapie-affected sheep, Br. Vet. J. (1974) 130:65-67.

[80] Philippe S., Ducrot C., Roy P., Remontet L., Jarrige N., Calavas D., Sheep feed and scrapie, France, Emerging Infect. Dis. (2006) 11:1274-1279.

[81] Race R., Jenny A., Sutton D., Scrapie infectivity and proteinase K-resistant prion protein in sheep placenta, brain, spleen, and lymph node: implications for transmission and antemortem diagnosis, J. Infect. Dis. (1998) 178: 949-953.

[82] Robinson M.M., Hadlow W.J., Knowles D.P., Huff T.P., Lacy P.A., Marsh R.F., Gorham J.R., Experimental infection of cattle with the agents of transmissible mink encephalopathy and scrapie, J. Comp. Pathol. (1995) 113:241-251.

[83] Ronzon F., Bencsik A., Lezmi S., Vulin J., Kodjo A., Baron T., BSE inoculation to prion diseasesresistant sheep reveals tricky silent carriers, Biochem. Biophys. Res. Commun. (2006) 350:872-877.

[84] Ryder S., Dexter G., Bellworthy S., Tongue S., Demonstration of lateral transmission of scrapie between sheep kept under natural conditions using lymphoid tissue biopsy, Res. Vet. Sci. (2004) 76:211-217.

[85] Sharpe A.H., Hunter J.J., Chassler P., Jaenisch R., Role of abortive retroviral infection of neurons in spongiform CNS degeneration, Nature (1990) 346:181-183.

[86] Schoon H.A., Brunckhorst D., Pohlenz J., Spongiforme encephalopathie beim Rothalsstrauss (Struthio camelus) Eim Kasuistischer Beitrag, Teirartztl. Prax. (1991) 19:263-265.

[87] Schoon H.A., Brunckhorst D., Pohlenz J., Beitrag zur neuropathology beim Rothalsstrauss (Struthio camelus) - Spongiforme Encephalopathie, Verh. Ber. Erkrg. Zootiere (Akademischer Verlag) (1991) 33: 309.

[88] Schätzl H.M., The phylogeny of mammalian and nonmammalian prion proteins, in: Hörnlimann B., Riesner D., Kretzschmar H. (Eds.), Prions in humans and animals, de Gruyter, Berlin, Germany, 2007, pp. 119-121.

[89] Sigurdson C.J., A prion disease of cervids: chronic wasting disease, Vet. Res. (2008) 39:41.
[90] Sisó S., Gonzalez L., Jeffrey M., Martin S., Chianini F., Steele P., Prion protein in kidneys of scrapie-infected sheep, Vet. Rec. (2006) 159:327-328.

[91] Somerville R.A., Oberthur R.C., Havekost U., MacDonald F., Taylor D.M., Dickinson A.G., Characterization of thermodynamic diversity between transmissible spongiform encephalopathy agent strains and its theoretical implications, J. Biol. Chem. (2002) 277:11084-11089.

[92] Soto C., Prions: the new biology of proteins, CRC Press, Florida, USA, 2006.

[93] St Rose S.G., Hunter N., Matthews L., Foster J.D., Chase-Topping M.E., Kruuk L.E., et al., Comparative evidence for a link between Peyer's patch development and susceptibility to transmissible spongiform encephalopathies, BMC Infect. Dis. (2006) 6:5.

[94] Taylor D.M., Woodgate S.L., Atkinson M.J., Inactivation of the bovine spongiform encephalopathy agent by rendering procedures, Vet. Rec. (1995) 137:605-610.

[95] Taylor D.M., Woodgate S.L., Fleetwood A.J., Cawthorne R.J., The effect of rendering procedures on scrapie agent, Vet. Rec. (1997) 141:643-649.

[96] Taylor D.M., Woodgate S.L., Rendering practices and inactivation of transmissible spongiform encephalopathy agents, Rev. Sci. Tech. (2003) 22:297310.

[97] Terry L.A., Marsh S., Ryder S.J., Hawkins S.A., Wells G.A., Spencer Y.I., Detection of disease-specific $\mathrm{PrP}$ in the distal ileum of cattle orally exposed to the agent of bovine spongiform encephalopathy, Vet. Rec. (2003) 152:387-392.

[98] Tongue S.C., Pfeiffer D.U., Warner R., Elliott H., del Rio Vilas V., Estimation of the relative risk of developing clinical scrapie: the role of prion protein (PrP) genotype and selection bias, Vet. Rec. (2006) 158:43-50.

[99] Touzeau S., Chase-Topping M.E., Matthews L., Lajous D., Eychenne F., Hunter N., et al., Modelling the spread of scrapie in a sheep flock: evidence for increased transmission during lambing seasons, Arch. Virol. (2006) 151:735-751.

[100] Tranulis M., Influence of the prion protein gene, Prnp, on scrapie susceptibility in sheep, APMIS (2002) 110:33-43.

[101] Tuo W., Zhuang D., Knowles D.P., Cheevers W.P., Sy M.S., O'Rourke K.I., $\mathrm{PrP}^{\mathrm{c}}$ and $\mathrm{PrP}^{\mathrm{Sc}}$ at the fetal-maternal interface, J. Biol. Chem. (2001) 276:18229-18234.

[102] Van den Ingh T.S., Mandigers P.J., van Nes J.J., A neuronal vacuolar disorder in young rottweiler dogs, Vet. Rec. (1998) 142:245-247.

[103] Van Keulen L.J., Schreuder B.E., Meloen R.H., Mooij-Harkes G., Vromans M.E., Langeveld J., Immunohistochemical detection of prion protein in lymphoid tissues of sheep with natural scrapie, J. Clin. Microbiol. (1996) 34:1228-1231. 
[104] Vascellari M., Nonno R., Mutinelli F., Bigolaro M., Di Bari M.A., Melchiotti E., et al., PrPSc in salivary glands of scrapie-affected sheep, J. Virol. (2007) 81:4872-4876.

[105] Vilotte J.L., Soulier S., Essalmani R., Stinnakre M.G., Vaiman D., Lepourry L., et al., Markedly increased susceptibility to natural sheep scrapie of transgenic mice expressing ovine PrP, J. Virol. (2001) 75:5977-5984.

[106] Wadsworth J.D., Asante E.A., Desbruslais M., Linehan J.M., Joiner S., Gowland I., et al., Human prion protein with valine 129 prevents expression of variant CJD phenotype, Science (2004) 306:17931796.

[107] Wells G.A., Scott A.C., Johnson C.T., Gunning R.F., Hancock R.D., Jeffrey M., et al., A novel progressive spongiform encephalopathy in cattle, Vet. Rec. (1987) 121:419-420.

[108] Wells G.A., Wells M., Neuropil vacuolation in brain: a reproducible histological processing artefact, J. Comp. Pathol. (1989) 101:355-362.

[109] Wells G.A., Dawson M., Hawkins S.A., Green R.B., Dexter I., Francis M.E., et al., Infectivity in the ileum of cattle challenged orally with bovine spongiform encephalopathy, Vet. Rec. (1994) 135:40-41.

[110] Wells G.A., Simmons M.M., The essential lesion profile of bovine spongiform encephalopathy (BSE) in cattle is unaffected by breed or route of infection, Neuropathol. Appl. Neurobiol. (1996) 22:453.

[111] Wells G.A., Hawkins S.A., Green R.B., Austin A.R., Dexter I., Spencer Y.I., et al., Preliminary observations on the pathogenesis of experimental bovine spongiform encephalopathy (BSE): an update, Vet. Rec. (1998) 142:103-106.

[112] Wells G.A., Hawkins S.A., Green R.B., Spencer Y.I., Dexter I., Dawson M., Limited detection of sternal bone marrow infectivity in the clinical phase of experimental bovine spongiform encephalopathy (BSE), Vet. Rec. (1999) 144:292-294.

[113] Wells G.A., Spiropoulos J., Hawkins S.A., Ryder S.J., Pathogenesis of experimental bovine spongiform encephalopathy (BSE): preclinical infectivity in tonsil and observations on the distribution of lingual tonsil in slaughtered cattle, Vet. Rec. (2005) 156:401-407.

[114] Wells G.A., Hawkins S.A., Austin A.R., Ryder S.J., Done S.H., Green R.B., et al., Studies of the transmissibility of the agent of bovine spongiform encephalopathy to pigs, J. Gen. Virol. (2003) 84:10211031.

[115] Wells G.A., Ryder S.J., Hadlow W.J., The pathology of prion diseases in animals, in: Hörnlimann B., Riesner D., Kretzschmar H. (Eds.),
Prions in humans and animals, de Gruyter, Berlin, Germany, 2007, pp. 315-323.

[116] Wells G.A., Pohlenz J., Hawkins S.A., Matthews D., Portrait of a spongiform encephalopathy in birds and the transmissibility of mammalian prion diseases to birds, in: Hörnlimann B., Riesner D., Kretzschmar H. (Eds.), Prions in humans and animals, de Gruyter, Berlin, Germany, 2007, pp. 279-282.

[117] Wells G.A., Konold T., Arnold M.E., Austin A.R., Hawkins S.A., Stack M., et al., Bovine spongiform encephalopathy: the effect of oral exposure dose on attack rate and incubation period in cattle, J. Gen. Virol. (2007) 88:1363-1373.

[118] Wilesmith J.W., Wells G.A., Cranwell M.P., Ryan J.B., Bovine spongiform encephalopathy: epidemiological studies, Vet. Rec. (1988) 123:638-644.

[119] Wilesmith J.W., Ryan J.B., Atkinson M.J., Bovine spongiform encephalopathy: epidemiological studies on the origin, Vet. Rec. (1991) 128:199-203.

[120] Wilesmith J.W., Ryan J.B., Hueston W.D., Bovine spongiform encephalopathy: case-control studies of calf feeding practices and meat and bonemeal inclusion in proprietary concentrates, Res. Vet. Sci. (1992) 52:325-331.

[121] Wilesmith J.W., Ryan J.B., Bovine spongiform encephalopathy: observations on the incidence during 1992, Vet. Rec. (1993) 132:300-301.

[122] Wilesmith J.W., Wells G.A., Ryan J.B., GavierWiden D., Simmons M.M., A cohort study to examine maternally-associated risk factors for bovine spongiform encephalopathy, Vet. Rec. (1997) 141:239-243.

[123] Williams E.S., Miller M.W., Portrait of chronic wasting disease in deer species, in: Hörnlimann B., Riesner D., Kretzschmar H. (Eds.), Prions in humans and animals, de Gruyter, Berlin, Germany, 2007, pp. 257-262.

[124] Wrathall A.E., Brown K.F., Sayers A.R., Wells G.A., Simmons M.M., Farrelly S., et al., Studies of embryo transfer from cattle clinically affected by bovine spongiform encephalopathy (BSE), Vet. Rec. (2002) 150:365-378.

[125] Wyatt J.M., Pearson G.R., Smerdon T.N., Gruffydd-Jones T.J., Wells G.A., Wilesmith J.W., Naturally occurring scrapie-like spongiform encephalopathy in five domestic cats, Vet. Rec. (1991) 129:233-236.

[126] Zlotnik I., Rennie J.C., A comparative study of the incidence of vacuolated neurons in the medulla from apparently healthy sheep of various breeds, J. Comp. Pathol. (1958) 68:411-415. 